\title{
Reply to comment on: Patti ME, McMahon G, Mun EC et al. (2005) Severe hypoglycaemia post-gastric bypass requiring partial pancreatectomy: evidence for inappropriate insulin secretion and pancreatic islet hyperplasia. Diabetologia 48:2236-2240
}

Received: 24 November 2005 / Accepted: 25 November 2005 / Published online: 3 February 2006

(C) Springer-Verlag 2006

\begin{abstract}
Abbreviations GLP1: glucagon-like peptide 1
\end{abstract}
\section{To the Editor:}

We appreciate the interest in our manuscript on hyperinsulinaemic hypoglycaemia post-gastric bypass [1] and the opportunity to respond to the concerns raised by Meier and colleagues [2]. While we hypothesize that excessive secretion of GLP1 may contribute to severe hyperinsulinaemia in the rare cases of post-bypass hypoglycaemia reported in our article [1], we agree it is important to acknowledge that factors other than GLP1 may play a mechanistic role. We also suggested additional potential mechanisms, including improved insulin sensitivity following weight loss unmasking an underlying familial hyperinsulinaemia syndrome, and lack of involution of increased beta cell mass that developed with prior obesity. Furthermore, a descriptive case series of three human patients, for which GLP1 levels are available for only two, makes conclusions regarding the pathogenic role of GLP1 secretion entirely speculative in

M. E. Patti $(\bowtie) \cdot$ S. Bonner-Weir $\cdot$ A. Goldfine

Research Division, Joslin Diabetes Center,

1 Joslin Place,

Boston, MA 02215, USA

e-mail: mary.elizabeth.patti@joslin.harvard.edu

Tel.: +1-617-7351981

Fax: +1-617-7351970

M. E. Patti · A. Goldfine

Department of Medicine,

Beth Israel Deaconess Medical Center,

Boston, MA, USA

M. E. Patti - S. Bonner-Weir - A. Goldfine

Harvard Medical School,

Boston, MA, USA nature. Markedly high levels of GLP1 in Patients 2 and 3, which peak by $30 \mathrm{~min}$ and return to baseline by $1 \mathrm{~h}$, do suggest that GLP1 could contribute to increased stimulation of insulin release in the early postprandial state when glucose levels are relatively increased. We have not observed increased GLP1 in the fasting or late postprandial state and therefore do not believe that GLP1 potentiates additional insulin secretion once hypoglycaemia has occurred. Thus, the early postprandial increases in GLP1 release and glucose could act in concert to stimulate insulin secretion during this period, resulting in the development of hypoglycaemia at subsequent postprandial time points.

We agree that while rodent data indicate that pharmacological doses of GLP1 stimulate beta cell proliferation, there are currently no data on the direct effects of GLP1 on beta cell mass in humans. In the single case report of a GLP1secreting tumour associated with postprandial hypoglycaemia, the pancreas was not evaluated, and this too must be considered purely anecdotal [3]. It is also important to note that in studies performed by Amylin Pharmaceuticals, extended ( 2 years) exposure to high levels of the GLP1 analogue exenatide did not cause pathological changes in islets in rodents, and exposure to 400 times the recommended human dose for 9 months causes minimal-to-mild islet hypercellularity without change in islet size in cynomolgus monkeys [4]. When testing the GLP1 hypothesis, it is important to evaluate whether GLP1 levels and responsiveness differ between affected subjects and other post-bypass patients. It would also be valuable to determine whether excessive insulin secretion occurs in these patients following intravenous glucose challenge. Clinical studies to address these important questions are in progress. NonGLP1-mediated mechanisms, including the potential effects of other incretins whose levels are altered following gastric bypass, should not be ignored. 
Meier and colleagues [2] also raise important questions regarding the increased islet area reported in our patients [1] and in the larger series of Service et al. [5]. The beta cell relative volumes of $3.3 \%$ (Patient 2, BMI $22 \mathrm{~kg} / \mathrm{m}^{2}$ ) and $10.5 \%$ (Patient 3, BMI $35 \mathrm{~kg} / \mathrm{m}^{2}$ ) were compared with data in the available published literature. Yoon et al. [6] report a range of $1.5-2.7 \%$ in nine donor pancreases from a Korean population, with no significant differences in relative volume in sections from different parts of the pancreas. There was a linear relationship between beta cell relative volume and BMI even across the limited BMI range evaluated $\left(21.5-26.8 \mathrm{~kg} / \mathrm{m}^{2}\right)$. Butler et al. [7] also demonstrated an important effect of weight on relative beta cell volume, reporting an increase of approximately $50 \%$ in obese nondiabetic individuals $\left(\mathrm{BMI}>27 \mathrm{~kg} / \mathrm{m}^{2}\right)($ mean \pm SEM: $2.6 \pm$ 0.4 vs $1.71 \pm 0.3 \%$ for obese vs lean subjects). In their letter, Meier and colleagues report that the upper limit of the range for beta cell volume in these obese non-diabetic persons extended to $10.5 \%$, though the degree of obesity of this individual is not provided. Given the standard error associated with measurements of the group, this patient may be a significant outlier, and the biology that underlies this magnitude of increased beta cell volume could be informative. While both of these studies suggest that obesity is associated with increased beta cell mass, there are presently no normative data to address the dynamics or expected range of beta cell mass in humans with a history of severe obesity followed by major weight reduction. Additional studies to address whether patients with post-bypass hypoglycaemia have inappropriate increases in beta cell mass relative to their BMI are clearly important. Similarly, it will be extremely valuable to determine whether the post-bypass state is associated with alterations in beta cell formation, including replication and/or neogenesis from ductal precursors. We would also like to suggest that hyperinsulinaemia per se, perhaps resulting from intrinsic beta cell dysfunction and accentuated by additional incretin factors, may also contribute to beta cell replication in this setting [8].

Finally, we would like to note that Patient 1 in our series did not show an improvement in hypoglycaemia following partial pancreatectomy, and required full pancreatectomy. Patients 2 and 3 in our series have likewise developed recurrent, though less severe, hypoglycaemia following partial pancreatectomy. Our experience in this limited number of patients appears to contrast with the efficacy of gradient-guided pancreatectomy reported by Service et al. for non-insulinoma prancreatogenous hypoglycaemia [9] and post-gastric bypass hypoglycaemia [5]. While these differences may reflect patient heterogeneity, these data also suggest that simple reduction of islet mass by guided partial pancreatectomy may not be a consistently effective therapeutic approach. Aggressive dietary measures, including frequent small meals, avoidance of carbohydrates with a high glycaemic index, treatment of nutritional deficiencies, and stepped pharmacological treatment to reduce insulin secretion and hypoglycaemia is clearly the mainstay of therapy at present, and is effective for the majority of patients. More broadly, these data suggest that, at least in some patients, there is likely to be a primary or intrinsic dysregulation of insulin secretion that is unmasked by the alterations in the metabolic milieu and improved insulin sensitivity following surgical weight loss.

\section{References}

1. Patti ME, McMahon G, Mun EC et al (2005) Severe hypoglycaemia post-gastric bypass requiring partial pancreatectomy: evidence for inappropriate insulin secretion and pancreatic islet hyperplasia. Diabetologia 48:2236-2240

2. Meier JJ, Nauck MA, Butler PC (2006) Comment to Patti ME, McMahon G, Mun EC et al (2005) Severe hypoglycaemia postgastric bypass requiring partial pancreatectomy: evidence for inappropriate insulin secretion and pancreatic islet hyperplasia. Diabetologia DOI 10.1007/s00125-005-0114-2

3. Todd JF, Stanley SA, Roufosse CA et al (2003) A tumour that secretes glucagon-like peptide-1 and somatostatin in a patient with reactive hypoglycaemia and diabetes. Lancet 361:228-230

4. Carpenter T, Trautmann ME, Baron AD et al (2005) Hyperinsulinemic hypoglycemia with nesidioblastosis after gastric-bypass surgery. N Engl J Med 353:2192-2194

5. Service GJ, Thompson GB, Service FJ, Andrews JC, CollazoClavell ML, Lloyd RV (2005) Hyperinsulinemic hypoglycemia with nesidioblastosis after gastric-bypass surgery. N Engl J Med 353:249-254

6. Yoon KH, Ko SH, Cho JH et al (2003) Selective beta-cell loss and alpha-cell expansion in patients with type 2 diabetes mellitus in Korea. J Clin Endocrinol Metab 88:2300-2308

7. Butler AE, Janson J, Bonner-Weir S, Ritzel R, Rizza RA, Butler PC (2003) Beta-cell deficit and increased beta-cell apoptosis in humans with type 2 diabetes. Diabetes 52:102-110

8. Hennige AM, Ozcan U, Okada T et al (2005) Alterations in growth and apoptosis of insulin receptor substrate-1-deficient beta-cells. Am J Physiol Endocrinol Metab 289:E337-E346

9. Service FJ, Natt N, Thompson GB, Grant CS et al (1999) Noninsulinoma pancreatogenous hypoglycemia: a novel syndrome of hyperinsulinemic hypoglycemia in adults independent of mutations in Kir6.2 and SUR1 genes. J Clin Endocrinol Metab 84:1582-1589 